\title{
Visualization of the Motion of Textiles through a Waste Water Pump at Different Operating Points
}

\author{
Henrik Sørensen, Anna Lyhne Jensen \\ Department of Energy Technology, Aalborg University, Aalborg, Denmark \\ Email: hs@et.aau.dk
}

How to cite this paper: Sørensen, H. and Jensen, A.L. (2018) Visualization of the Motion of Textiles through a Waste Water Pump at Different Operating Points. Journal of Flow Control, Measurement \& Visualization, 6, 39-47.

https://doi.org/10.4236/jfcmv.2018.61004

Received: September 6, 2017

Accepted: January 23, 2018

Published: January 26, 2018

Copyright $\odot 2018$ by authors and Scientific Research Publishing Inc. This work is licensed under the Creative Commons Attribution International License (CC BY 4.0).

http://creativecommons.org/licenses/by/4.0/

\begin{abstract}
In this paper, the motion of textiles through a waste water pump is studied by aid of vision technologies. The steel volute of a commercial pump is replaced with a similar volute made in acrylic glass, which allows recording the motion of textiles inside the pump. Recordings are made at four different operating points to investigate the influence of rotational speed of the impeller and flow rate on the passage of textiles through the pump. The experiments show that the textiles flow rapidly through the pump when the pump is operated near the best efficient point for both high and low impeller speed. The textiles tend to stay inside the pump when the pump is operated at part load for both low and high impeller speed. At low impeller speed, the textiles often stick to the tongue in the pump casing. At higher impeller speed, the textiles flow multiple rounds in the volute. For fail-safe operation, it is recommended not to operate waste water pumps far away from the best efficiency point.
\end{abstract}

\section{Keywords}

Pump, Artificial Waste Water, Textile, Clogging, Visualization

\section{Introduction}

At the time being, waste water systems around the world are challenged by an increased amount of synthetic products in the waste water. Items like flannels, sanitary towels, cotton buds, condoms and wet wipes are flushed in toilets, and afterwards they flow through pipes and pumps towards the wastewater treatment plant, where they are sorted out in mechanical filters. On their way, especially the passages of wastewater pumps are critical as the synthetic solid parts of the wastewater can cause stoppage due to clogging of impellers. Pöhler et al. [1] 
reports that more than 12,000 failures are seen yearly in Berlin, where the majority of these failures are due to clogging. Universities and pump manufactures collaborate in research on wastewater topics to gain a better understanding of the clogging and to be able to solve these problems on pumping wastewater containing solid objects. One way of getting a better understanding of how to avoid these problems is through a comprehensive experimental program like presented by Thamsen [2], where different scenarios are studied. This approach is expensive and often limited to a single or maximum a few pump designs. As a result of this, an effort is made to develop reliable computational models, where simulations will replace the experimental programs. For clean water applications simulations have proven to be an accurate and powerful tool for pump development [3], while the development in simulation tools for complex flows including a carrier phase (water) and foreign objects are under rapid development. Boundary conditions for the latter type of simulations can be obtained like in Jensen et al. [4], where the influence of operating point on the shape and position of textile material at the inlet pipe to a dry-installed wastewater pump is investigated. Having the right boundary conditions for these types of simulations, the next step is to gather information to validate the new models. Gerlach et al. [5] did a comprehensive study of vortex pump impeller designs, where the clogging behavior was studied through experiments utilizing artificial wastewater and a pump with a transparent housing. Recently, Tan et al. [6] reported an experimental study of pass-through and collision characteristics of coarse particles $(6-15 \mathrm{~mm})$ in a radial impeller mounted in a transparent pump facility. Common for the research done by Jensen et al., Gerlach et al. and Tan et al. is that the experiments were carried out in dry-installed pumps and without focus on the movement of textiles.

Since a significant number of pumps are wet-installed [7], there is also a need for further research involving this type of pumps. The aim of this paper is to provide detailed information on how textile flows through a wet-installed pump operated at the best efficiency point (BEP) and part load (55\% of BEP).

\section{Methods}

\subsection{Experimental Setup and Instrumentation}

The movement of dust cloths flowing through the pump is filmed by an industrial camera placed outside the test rig with its optical axis normal to the rotational plane of the impeller. The camera view angle is shown in Figure 1 (middle). The impeller is rotating counter clock wise seen from the camera view. All images are stored as jpeg-files on a personal computer for later analysis. Specifications of the optical components are presented in Table 1.

In this experiment a prototype pump with an acrylic pump casing is used. The impeller is an asymmetric single channel S-tube impeller made in cast iron. The free passage through the impeller is $80 \mathrm{~mm}$. The impeller geometry is shown in Figure 2. The pump is equipped with a $2.9 \mathrm{~kW} 4$-pole motor. At nominal speed, the 

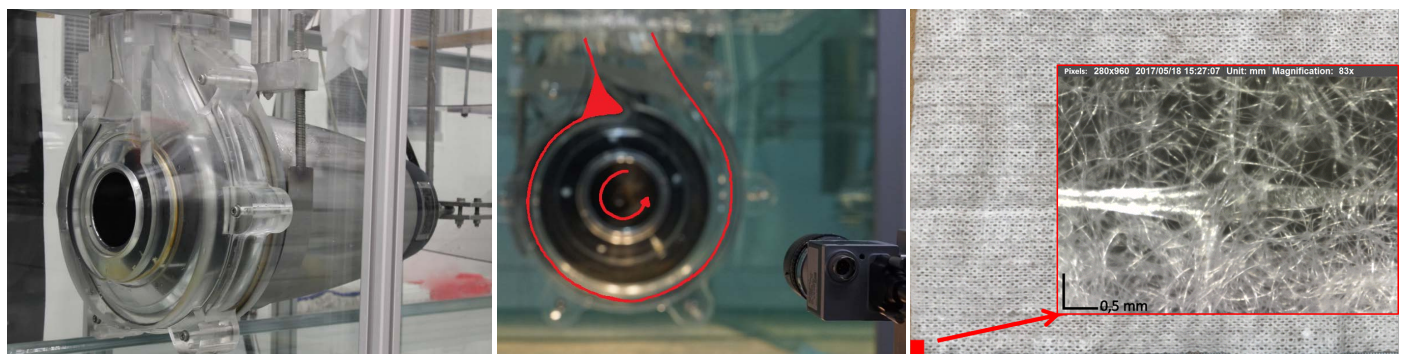

Figure 1. Left: Wastewater pump with acrylic pump casing used in the experiments. Middle: The pump casing seen from camera angle. The outer contour of the volute is marked with a red line. The tongue is the triangle region marked with red. Seen from camera angle the impeller is rotating counter clock wise. Right: Zoomed view of the Aro Non-woven synthetic dust cloth used in the experiment.

Table 1. Specification and settings of the camera used in the experiments.

\begin{tabular}{cc}
\hline Camera model & Basler acA $1920-155 \mathrm{um}$ \\
Exposure time & $350 \mu \mathrm{s}$ \\
Frame rate & $100 \mathrm{fps}$ \\
Resolution & 1044 pixel $\times 1344$ pixel \\
Lens & COSMICAR/PENTAX TV LENS $25 \mathrm{~mm}$ \\
FOV & $211 \mathrm{~mm} \times 271 \mathrm{~mm}$ \\
\hline
\end{tabular}

maximum flow rate is $133 \mathrm{~m}^{3} / \mathrm{h}$ and the maximum head is $11.6 \mathrm{~m}$. The best efficiency point is located at $116 \mathrm{~m}^{3} / \mathrm{h}$. The pump has a relative high specific speed of 81 . The installation of the pump is illustrated in Figure 1 (left). The pump is connected to a variable speed drive which makes it possible to adjust the impeller speed to a given rpm. For flow measurements the test rig is equipped with an electromagnetic flow meter (Danfoss MAG3000). For the test reported in this work the operating points of the pump were adjusted using $48 \mathrm{~mm}$ and $80 \mathrm{~mm}$ flow restrictors.

The textile material used in these experiments is Aro super dust cloths made for house hold cleaning. The research group led by Thamsen at Technical University Berlin has found that the Aro super dust cloth can be used as an artificial substitution of waste water. The dust cloths are $220 \mathrm{~mm} \times 300 \mathrm{~mm}$ and have a thickness of $0.77 \mathrm{~mm}$. The material is non-woven polyester (90\%) and polypropylene $(10 \%)$. The material structure of the dust cloths is shown in Figure 1 (right). To ensure the right wetting of the dust cloths, they were stored in water for minimum 24 hours before the tests were carried out.

\subsection{Experiment Cases}

For the experiments included in this paper the impeller speed was set to 600rpm or $1200 \mathrm{rpm}$. Flows at best efficiency point $\left(\mathrm{Q}_{\mathrm{BEP}}\right)$ and heavy part load (55\% of flow at $\mathrm{Q}_{\mathrm{BEP}}$ ) were tested for both impeller speeds. This parameter variation gives in total 4 different test cases (see Table 2), where 50 runs were carried out for each case. In total 298,677 images were recorded for this experiment.

\subsection{Experimental Procedures}

The operating points of the pump were adjusted by mounting the right flow re- 


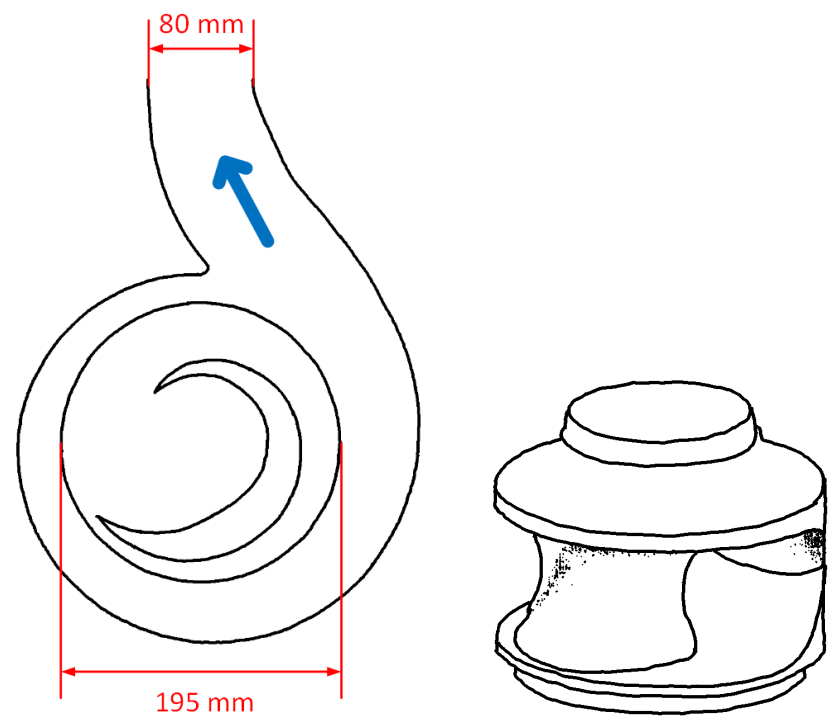

Figure 2. Left: Plane sketch of the prototype volute and impeller for mid sectional view. The impeller rotates counter clock wise. Right: Sketch of prototype S-type impeller.

Table 2. Impeller speed and flow settings for the experimental test cases.

\begin{tabular}{ccc}
\hline & $\mathrm{Q} / \mathrm{Q}_{\mathrm{BEP}}=100 \%$ & $\mathrm{Q} / \mathrm{Q}_{\mathrm{BEP}}=55 \%$ \\
\hline Head (Impeller speed $600 \mathrm{rpm})$ & $0.82 \mathrm{~m}$ & $1.35 \mathrm{~m}$ \\
Head (Impeller speed $1200 \mathrm{rpm})$ & $3.27 \mathrm{~m}$ & $5.39 \mathrm{~m}$ \\
\hline
\end{tabular}

strictor and setting the frequency on the variable speed drive. The experiments were started when the flow through the pump was stationary. In the experiment un-crumpled dust cloths were released in the sump around the pump. The dust cloths were replaced when they had visible damages. Video recordings were started manually when the dust cloth entered the region around the pump inlet. All acquired images were streamed to the hard drive of a computer

\subsection{Data Treatment}

The image sequences are afterwards analyzed through an inhouse vision program, where the dust cloth is identified inside the pump. The image processing steps are shown in Figure 3. Primary information as time, size and position is stored. The retention time in the volute is then calculated as the time between cloth entered and left the pump casing. The time for one rotation in the pump casing is also calculated for cloths taking more than one round in the pump casing.

\subsection{Flow Measurement}

Measurements by aid of Particle Image Velocimetry were carried out by Bjerg et al. [8] prior to the main research presented in this article. Due to this fact the operation point is slightly different. The flow is measured near the tongue by Particle Image Velocimetry to investigate the local velocity field when the pump is operated at high flow rate $\left(90 \%\right.$ of $\left.\mathrm{Q}_{\mathrm{BEP}}\right)$ and low flow rate $\left(60 \%\right.$ of $\left.\mathrm{Q}_{\mathrm{BEP}}\right)$. 


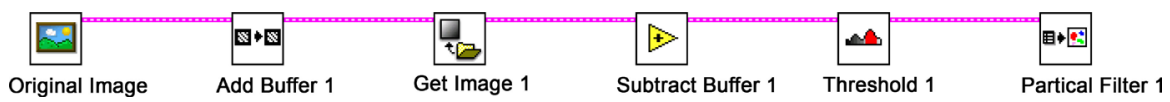

Figure 3. Image processing steps in NI Vision for detection of the textile inside the volute.

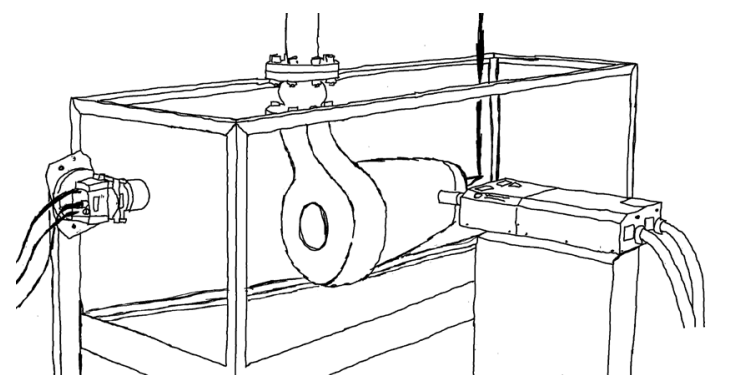

Figure 4. Schematic view of PIV setup for flow measurements inside the volute of the pump.

The system is calibrated to achieve accurate measurements inside the complex shaped pump casing. In each experiment 900 image pairs were taken. An adaptive correlation algorithm is used for data processing. The initial IA size is $128 \times$ 128 pixel with 2 refinement steps resulting in a final IA size of $32 \times 32$ pixel. The flow is seeded with polyamide particles with a diameter of $20 \mu \mathrm{m}$. The setup is sketched in Figure 4.

\section{Results}

The output of the experiments contains almost 300,000 images, which are impossible to present on paper. Instead informative selected sequences are extracted and presented.

\subsection{Operation near Best Efficiency Point at 600 rpm}

The cloths flow relatively smoothly through the pump when operated near best efficiency point at low impeller speed $(600 \mathrm{rpm})$. Based on the 50 runs the average retention time in the volute is calculated to $0.8 \mathrm{~s}$. Inspection of the 50 cases shows that in 19 out of the 50 runs the textiles shortly sticks to the tongue for $0.5-2.0 \mathrm{~s}$. In two cases, the textile sticks to tongue for a longer period of $7-8 \mathrm{~s}$. Figures 5(a)-(h) shows an example of how a cloth flows out of the volute. Figure 5(g) shows how the cloth shortly sticks to the tongue before leaving the volute.

\subsection{Operation at Part Load and $600 \mathrm{rpm}$}

The cloths tend to be trapped at the tongue for longer time when the pump is operated at low speed and part load (55\% of $\left.\mathrm{Q}_{\mathrm{BEP}}\right)$. In total 26 out of 50 runs show the cloth trapped on the tongue. In 18 of the 26 cases the experiment was stopped after 30s for removal of the cloth. Inspection of the recorded image series shows that the cloths are trapped within one or two revolutions in the volute. The average time for one rotation of the cloth in the volute is $435 \mathrm{~ms}$. Figures 6(a)-(d) shows an example of how a cloth running with an impeller speed 

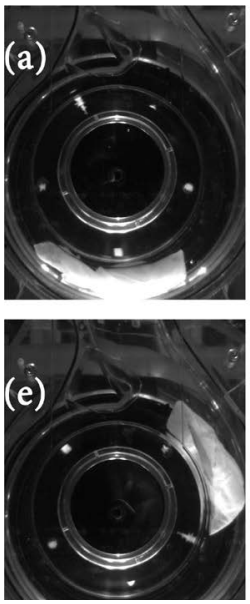
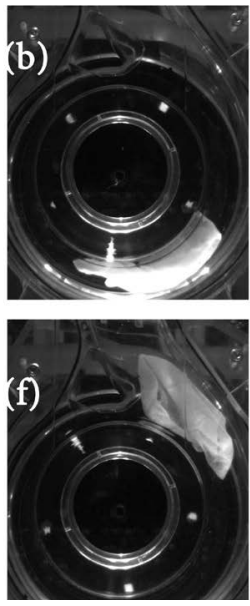
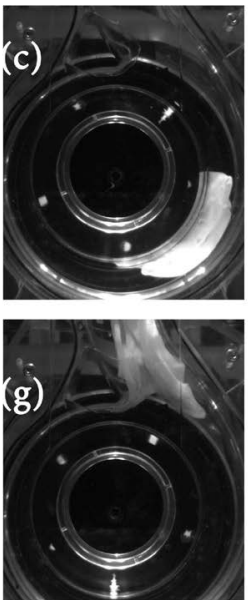
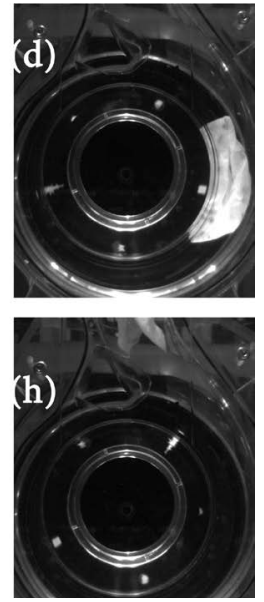

Figure 5. Sequence of images showing the dust cloth passing through the volute of the pump running with an impeller speed of $600 \mathrm{rpm}$ at best efficiency point. The selected pictures (a)-(h) have an inter frame time of $40 \mathrm{~ms}$.
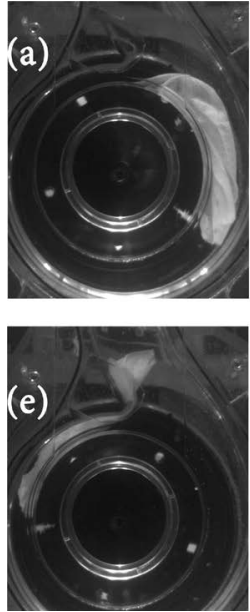
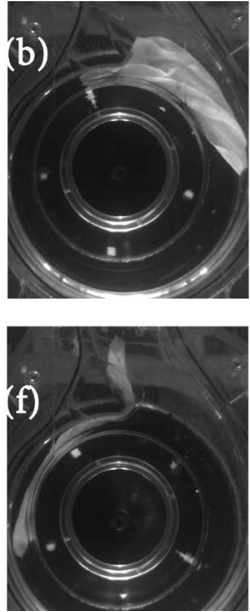
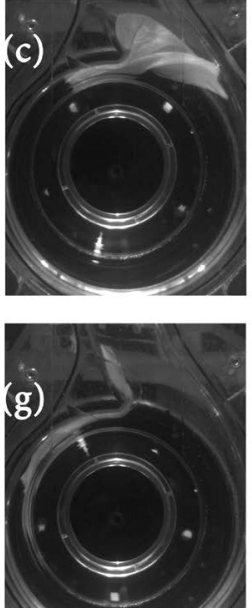
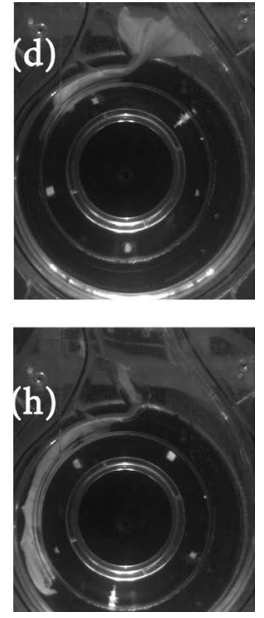

Figure 6. Sequence of images showing the dust cloth sticking to the tongue in the volute. The pump is running with an impeller speed of $600 \mathrm{rpm}$ at part load ( $55 \%$ of $\left.\mathrm{Q}_{\mathrm{BEP}}\right)$. The selected pictures (a)-(h) have an inter frame time of $40 \mathrm{~ms}$.

of $600 \mathrm{rpm}$ at best efficiency point. The selected pictures (a)-(h) have an inter frame time of $40 \mathrm{~ms}$ is approaching the tongue and aligns on it for a short period. In Figure $6(\mathrm{~g})$ \& Figure $6(\mathrm{~h})$ the cloth is seen being dragged along the outer surface of the volute.

\subsection{Operation near Best Efficiency Point at 1200 rpm}

Most of cloths flow directly through the pump when operated at $1200 \mathrm{rpm}$ at the best efficiency point. Only 3 out of 50 cloths stay in the volute for more than one rotation. The average retention time in the volute is calculated to $239 \mathrm{~ms}$. Inspection of the image series shows that the cloth only in one case aligns shortly on the tongue for a few milliseconds and quickly continues out of the volute see Figure 7. In two cases, the cloth is attached to the leading edge of the impeller for less than one revolution. 

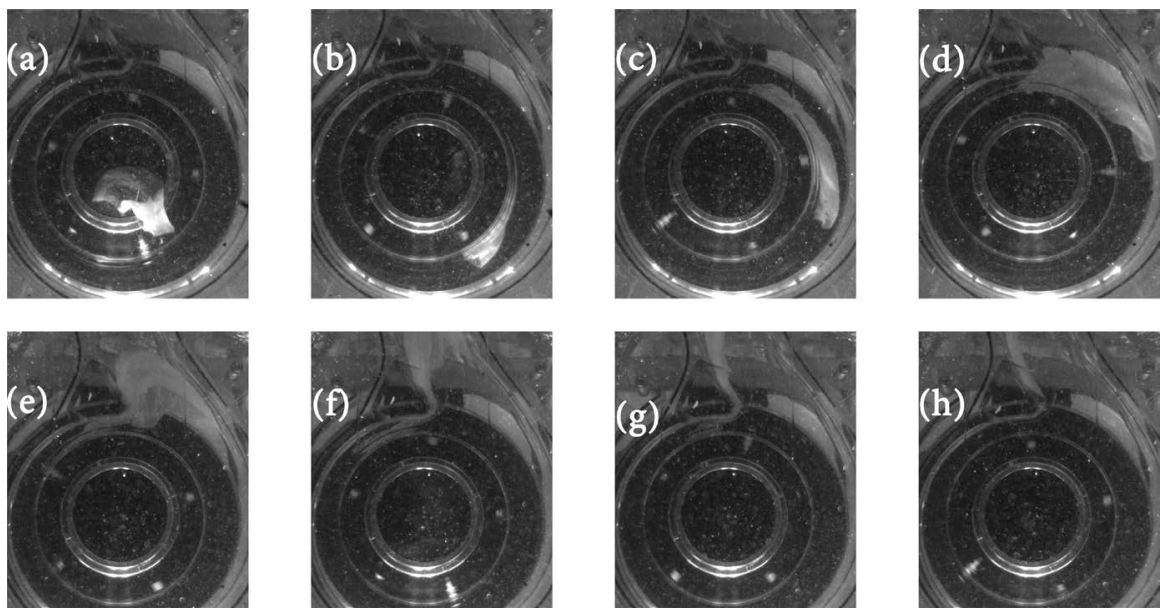

Figure 7. Sequence of images showing the dust cloth passing through the volute. The pump is running with an impeller speed of $1200 \mathrm{rpm}$ at best efficiency point. The selected pictures (a)-(h) have an inter frame time of $20 \mathrm{~ms}$.

\subsection{Operation at Part Load and 1200 rpm}

In the experiment where the pump was operated in part load at $1200 \mathrm{rpm}$ the cloth tends to stay inside the volute for multiple rotations. In 42 out of 50 runs the cloth took more than 15 revolutions (retention time $>2.7 \mathrm{~s}$ ). The average time for one rotation of the cloth in the volute is $179 \mathrm{~ms}$. In 4 out of 50 runs the cloth sticks to the tongue for a short period before being dragged out in the volute and continuing in the flow for multiple rotations as seen in Figures 8(a)-(h). For all the 50 runs carried out at this operating point the cloth succeeded to leave the volute within 20 seconds from the time of arrival.

\subsection{Discussion}

This experiment does not show any results which may give causes for concerns when the pump is operated at a flow near the best efficiency point. But when the pump operates in part load ( $55 \%$ of $\mathrm{Q}_{\mathrm{BEP}}$ ) the cloth tends to stay inside the pump. For low impeller speed the cloth sticks to the tongue and for high impeller speed the cloth simply flows around at the circumference of the impeller. An explanation of these two phenomena is that the flow in the near tongue region is changing when the pump is operated in part load. Measurements by aid of Particle Image Velocimetry done in advance by Bjerg et al. [8] reveal the flow change. Compared to a high flow rate through the pump a relative larger amount of the fluid is just moving around in the volute, when the pump is operated at lower flow rates. The physical explanation of this change is that for lower flow rates the pressure at the pump outlet increases and thereby the pressure difference across the tongue region also increases. The relative change of the flow is shown in Figure 9 (right). This change in local velocity distribution causes the cloth to be dragged away from the outlet of the volute towards the tongue region. The findings in this research support the conclusions in [2] where it is stated that clogging occurs in heavy part load and low speeds. 

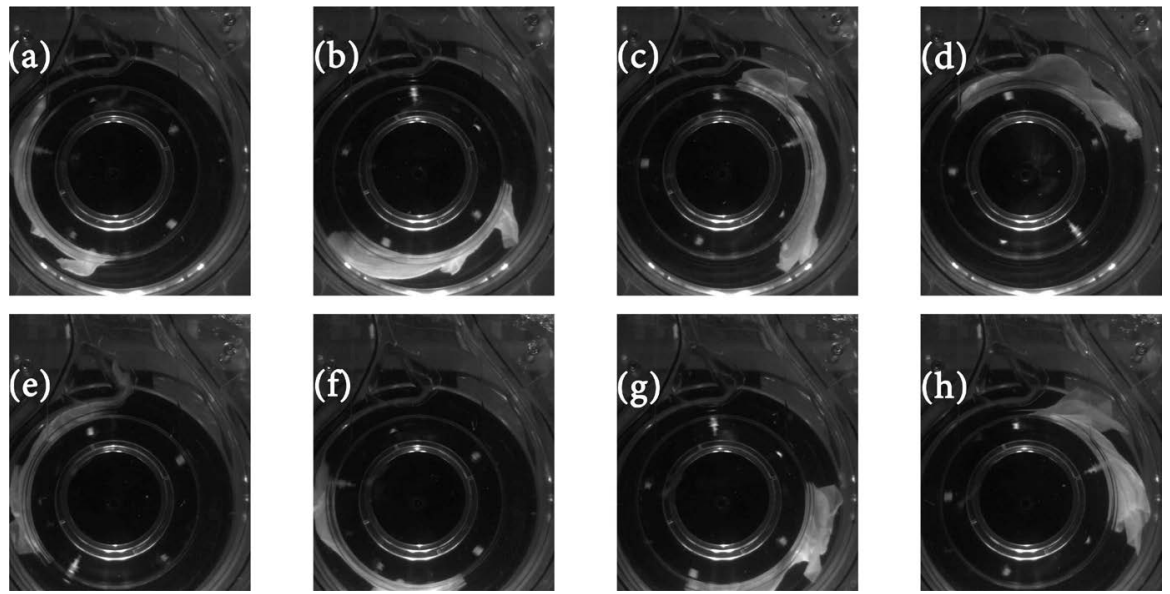

Figure 8. Sequence of images showing the dust cloth sticking to the tongue in the volute. The pump is running with an impeller speed of $1200 \mathrm{rpm}$ at part load $\left(55 \%\right.$ of $\left.\mathrm{Q}_{\mathrm{BEP}}\right)$. The selected pictures (a)-(h) have an inter frame time of $40 \mathrm{~ms}$.
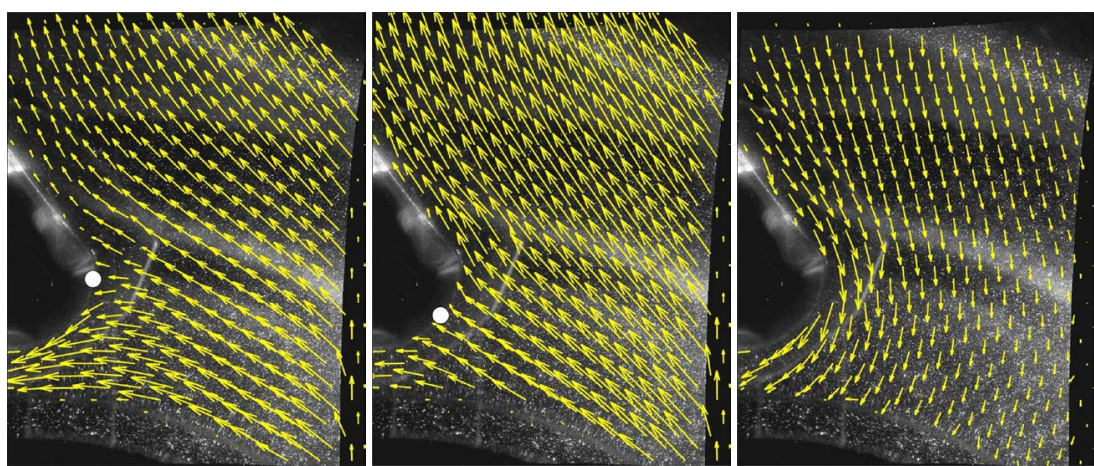

Figure 9. Left: Flow pattern for $60 \%$ of $\mathrm{Q}_{\mathrm{BEP}}$. Middle: Flow pattern for $90 \%$ of $\mathrm{Q}_{\mathrm{BEP}}$. Right: Relative flow around the tongue when changing the flow from $90 \%$ of $\mathrm{Q}_{\mathrm{BEP}}$ to $60 \%$ of $\mathrm{Q}_{\mathrm{BEP}}$.

\section{Conclusion}

For both high and low impeller speed, the wastewater pump tested in this study is working as intended, when the operation point is around the $\mathrm{Q}_{\text {вер}}$. For part load ( $55 \%$ of $\mathrm{Q}_{\mathrm{BEP}}$ ), the cloth stays inside the pump for several seconds, which increases the risk of damages of the cloth. This can lead to unraveled textile which can flow into cavities or groves and cause serious problems over time.

\section{Acknowledgements}

This work is based on selected parts of an extensive amount of experimental work, where a number of students have assisted in the acquisition of the raw data. The authors appreciate this assistance and express their gratitude to Arberg, E., Blæsbjerg, L., Ruddæk, M., Ravn, E., Vestdam, K., Olafson, G. and Dueholm, R. for their effort in this part.

\section{References}

[1] Pöhler, M., Gerlach, S., Höchel, K., Mengdehn, T. and Thamsen, P.U. (2015) Link- 
ing Efficiency to Functional Performance by a Pump Test Standard for Wastewater Pumps. Proceedings of the ASME-JSME-KSME Joint Fluids Engineering Conference-AJK2015, Seoul, 26-31 July 2015, 2529-2535.

[2] Thamsen, P.U. (2009) Cutting Clogging in Wastewater. World Pumps, 511, 22-25. https://doi.org/10.1016/S0262-1762(09)70140-3

[3] Hirschberger, M., Kuhlmann, J. and Benra, F.-K. (2009) Designing High-Power Sewage Water Pumps. World Pumps, 2009, 20-25. https://doi.org/10.1016/S0262-1762(09)70245-7

[4] Jensen, A.L., Gerlach, S., Lykholt-Ulstrup, F., Sørensen, H., Rosendahl, L. and Thamsen, P.U. (2017) Investigation of the Influence of Operating Point of the Shape and Position of Textile Material in the Inlet to a Dry-Installed Wastewater Pump. Proceedings of ASME 2017 Fluids Engineering Division Summer Meeting-FEDSM 2017, Waikoloa, HI, 30 July-3 August 2017. https://doi.org/10.1115/FEDSM2017-69298

[5] Gerlach, A., Wullf, S., Perlitz, D., Lykholt-Ustrup, F. and Thamsen, P.U. (2017) The Optimal Vortex Pump Impeller-An Experimental Study on Clogging Behaviour. Proceedings of 12 th European Conference on Turbomachinery Fluid Dynamics and Thermodynamics, Stockholm, 3-7 April 2017, 1-10.

[6] Tan, M., Lian, Y., Liu, H., Wu, X. and Ding, R. (2017) Visualizing Test on the Pass-Through and Collision Characteristics of Coarse Particles in a Double Blade Pump. International Journal of Naval Architecture and Ocean Engineering, 10, 1-8.

[7] Berezin, S. (2007) Wet and Dry Installation of Submersible Pumps. World Pumps, 2007, 44-48. https://doi.org/10.1016/S0262-1762(07)70364-4

[8] Bjerg, A., Winther, K., Christoffersen, K.F., Steenstrup, M.V. and Noarapast, M. (2016) Investigation of the Flow in the Near-Tongue Region of a Waste Water Pump. Internal Technical Report, Aalborg University, Denmark. 